\title{
Ciência e Tecnologia em um mundo de ponta-cabeça
} GLAUCO ARBIX ${ }^{I}$

"Em quatro meses, [a pandemia] devastou o mundo inteiro... Onde vai acabar? Estamos ainda no começo.”

(Dr. Anthony Fauci $)^{1}$

UDO INDICA que o século XXI terá de renascer após a pandemia. Apesar dos imensos avanços da Ciência e da Tecnologia (C\&T), a humanidade foi

L surpreendida por eventos há muito anunciados, mas nunca levados suficientemente a sério por autoridades de países desenvolvidos e emergentes. Sinais dolorosos enviados pelas epidemias do ebola, varíola, H1NI e Sars, para citar as mais recentes, não serviram de alerta para governos e instituições e foram acomodadas em círculos e redes de pesquisa, não raramente desdenhados em suas advertências.

A Covid-19, ainda em desenvolvimento, já deixou profundas cicatrizes na face do planeta. Não foi a primeira pandemia, é certo. Mas é a mais letal dos últimos 100 anos. Após a gripe espanhola de 2018, que castigou o planeta por 15 meses, e matou cerca de 50 milhões de pessoas, a ciência aprendeu sobre o vírus, descobriu vacinas, desenvolveu a cura de doenças e estruturou redes de proteção e de saúde pública. O que ajudou a controlar sua expansão e a mitigar efeitos perversos, sem conseguir, no entanto, conter seu impacto desorganizador das sociedades.

A atual crise gerada pela Covid-19 já deixou em seu rastro pelo menos três grandes marcas: a primeira está cravada no alto custo em vidas e sequelas que feriram populações imensas em um curto espaço de tempo; a segunda responde pela aguda recessão e consequente diminuição do emprego, de salários e de renda, fechamento de empresas e desorganização da economia, com aumento das desigualdades e da pobreza; a terceira está ligada à corrosão institucional e à disseminação do medo e da perplexidade na sociedade.

A enorme onda de insegurança que percorre os países afetará de maneira duradoura o modo de se viver e trabalhar, com impactos de longa duração na economia mundial, particularmente danosos aos países em desenvolvimento como o Brasil. As decisões de hoje desenharão os contornos das sociedades para as próximas gerações, que terão de aprender a conviver com a incerteza. Essa nova realidade terá especial significado para a educação, para a produção 
de ciência e a tecnologia. E exigirá mudanças substantivas de nossas escolas e universidades.

\section{O mundo de ponta-cabeça}

A conclusão acima é do Committee for the Coordination of Statistical Activities (CCSA), organização supranacional, que reúne mais de 30 instituições, da ONU, OMS ao Banco Mundial, e tem como principal ofício a geração de dados estatísticos confiáveis. Pelo CCSA o mundo ficou sabendo que, em abril de 2020, a pandemia tomou conta de mais de 200 países e matou 17 pessoas por minuto. Até maio, a crise gerada pela Covid-19 havia empurrado para a pobreza extrema cerca de 60 milhões de pessoas, e mesmo em países mais ricos, 36\% das famílias esgotaram seus recursos básicos após três meses sem renda.

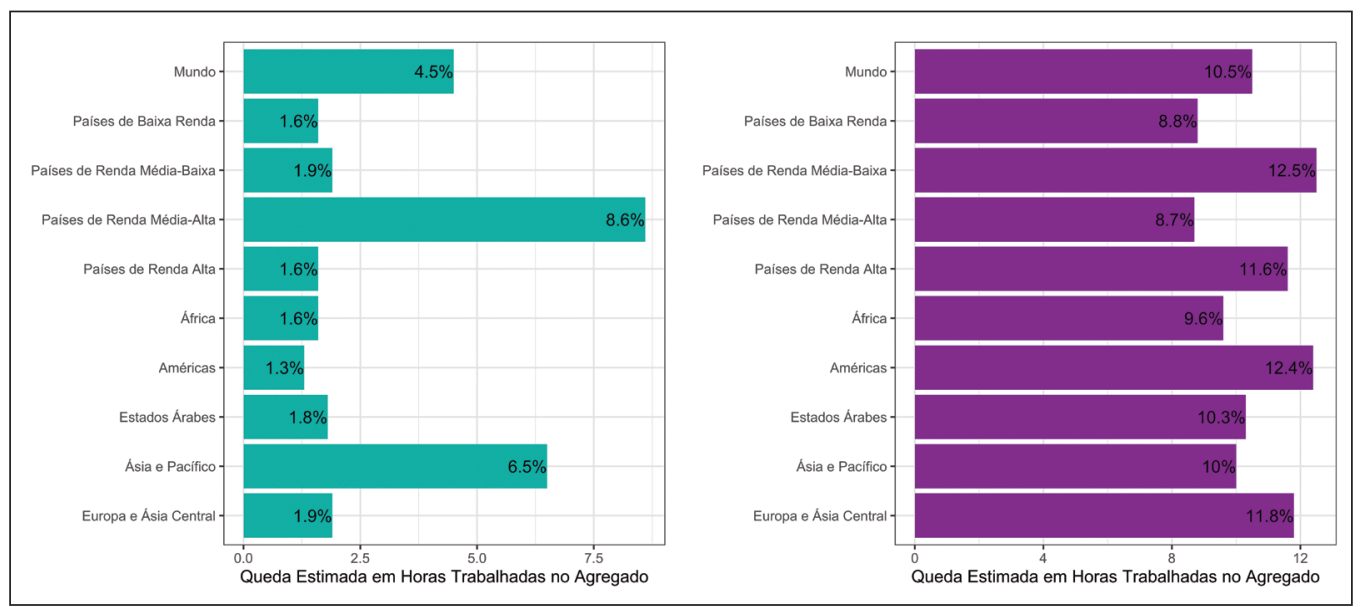

Fonte: International Labor Organization, May 2020.

Gráfico 1 - Queda estimada das horas de trabalho (agregado).

No plano mundial, o impacto sobre o emprego é o maior desde a Segunda Guerra Mundial, com perdas agregadas de mais de $10 \%$ de horas agregadas de trabalho, ou o equivalente a 305 milhões de trabalhadores em jornada integral. Essa é a maior causa da ampliação da condição de vulnerabilidade, antessala da extrema pobreza.

Cálculos da Rede de Pesquisa Solidária² para o Brasil apontam para a dimensão do impacto:

- Um quarto dos trabalhadores brasileiros (23,8 milhões de pessoas) foram identificados como vulneráveis em razão da pandemia. Ou seja, trabalhadores que já perderam a condição anterior de estabilidade de renda.

- Mais de 70 milhões de pessoas (cerca de 80\% da força de trabalho) passou a experimentar algum tipo de vulnerabilidade em meio à crise.

- A distribuição dos grupos vulneráveis nas unidades da federação é basicamente homogênea, o que significa que todos os estados brasileiros terão seus mercados de trabalho afetados de forma semelhante. $\mathrm{Ou}$ 
seja, os trabalhadores identificados como mais vulneráveis, seja em São Paulo, seja no Maranhão, respectivamente o estado mais rico e o mais pobre do país, estão igualmente sujeitos à perda significativa do emprego ou à deterioração da renda. Os trabalhadores, que ocupam posições e vínculos mais instáveis em setores considerados pelo governo como não essenciais, pertencem ao grupo dos extremamente vulneráveis.

A perda de renda, do emprego, diminuição da jornada de trabalho, redução salarial ou a impossibilidade de acesso ao mercado (situação especialmente crítica para os trabalhadores informais) já empurrou cerca de 60 milhões de pessoas para a extrema pobreza em todo o mundo.

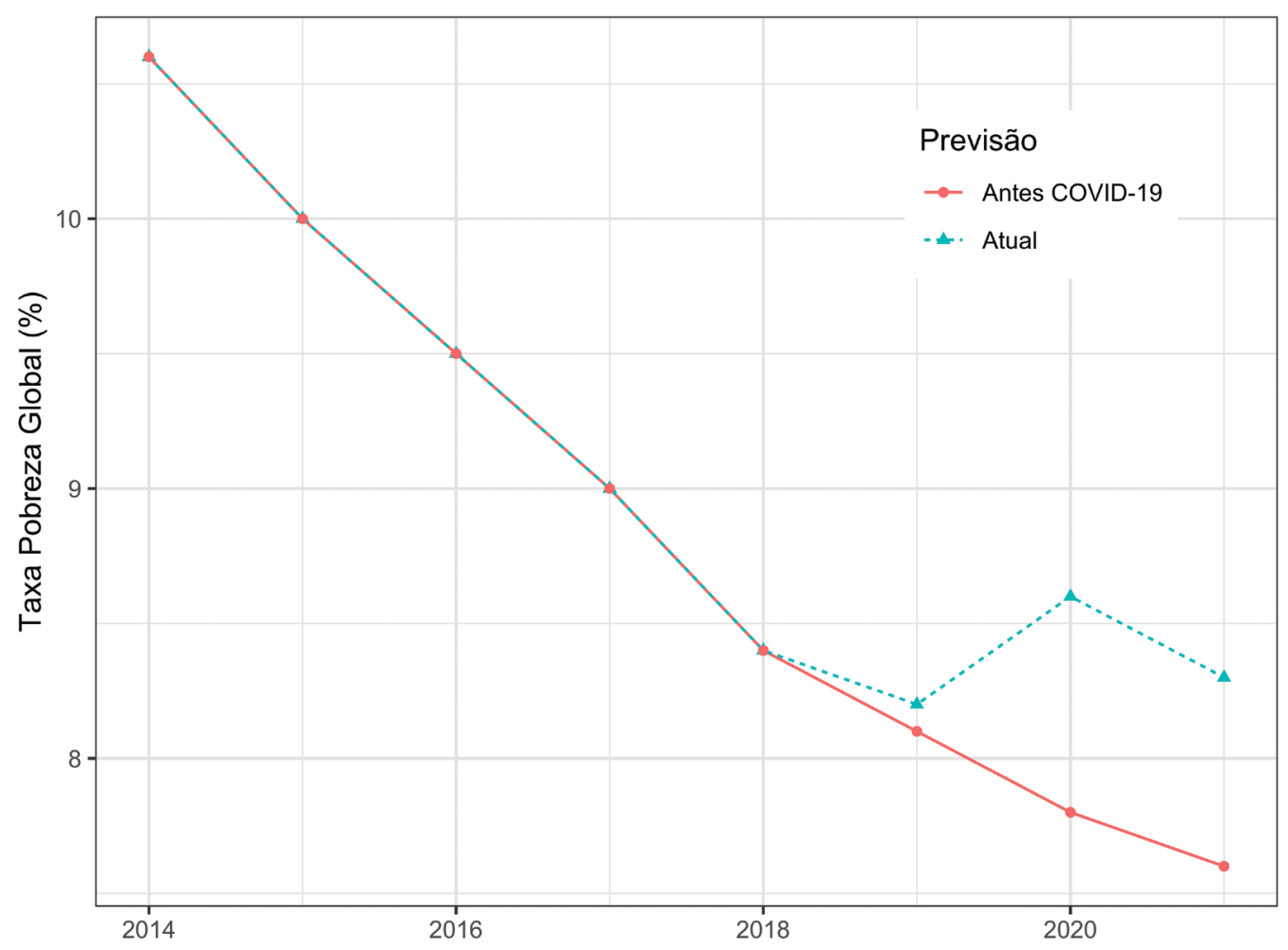

Fonte: CCSA. How Covid-19 is changing the world: a statistical perspective. June, 2020.

Gráfico 2 - Impacto da Covid-19 na Pobreza Global.

No Brasil, pesquisadores identificaram diferenças na condição de vulnerabilidade entre homens e mulheres, assim como entre negros e brancos. A diferença da vulnerabilidade de negros(as) e brancos(as) é resultado das diferenças de vínculo: brancas(os) têm vínculos mais estáveis e negras(os) têm vínculos mais frágeis.

Projeção feita por pesquisadores da USP, do Centro Brasileiro de Análise e Planejamento (Cebrap) e do Centro de Estudos da Metrópole (CEM) captou uma nova dimensão da vulnerabilidade: homens brancos e mulheres brancas entraram na condição de "novos vulneráveis". Apesar de gozarem de maior es- 
tabilidade, estavam empregados em setores não essenciais, que paralisaram suas atividades. Essas mesmas pesquisas mostraram que os grupos "tradicionalmente vulneráveis", compostos por homens e mulheres negras são mais vulneráveis que os "novos vulneráveis". 3

A desarticulação do mercado de trabalho certamente se erguerá como um dos maiores obstáculos à recuperação da economia, assim como o aumento das desigualdades e da pobreza dificultarão a estabilidade social.

\section{Ponto de não retorno}

Crises, em geral, revelam o pior e o melhor das sociedades. Após os ataques terroristas do 11 de Setembro, os mais diferentes governos aumentaram os dispositivos de vigilância sobre seus cidadãos a vigilância governamental dos cidadãos aumentou exponencialmente e novas guerras explodiram. Após a quebra das finanças em 2008, os bancos retornaram às condições anteriores por conta da ajuda de governos e de cortes em serviços públicos essenciais. Mas as crises também tornam possível alterações no próprio tecido da normalidade. Expectativas dissonantes desse calibre estão presentes nas análises atuais, em diferentes campos e disciplinas.

Nas atividades de Ciência e Tecnologia (C\&T) não poderia ser diferente.

A crise atual aponta para uma inflexão na trajetória dos países, em especial dos países emergentes como o Brasil que exibe um crescimento desordenado da dívida pública, queda do investimento externo, dificuldades fiscais e esgotamento das empresas. Diminuição do emprego, da renda e aumento da pobreza purgarão como chagas abertas por um longo período. Os impactos da Covid-19, para além do rastro de sofrimento e desolação no curto prazo, exigirá mudanças na atividade econômica, no universo da política, nas relações com o meio ambiente, na educação e na C\&T. E uma sintonia fina entre a razão política e a econômica, como afirma Jeffrey Frieden (2020, p.9), professor de Harvard,

A Economia Política estuda e explicíta a integração de fatores econômicos e políticos na sociedade moderna. É praticamente consenso que política e economia estão intricada e irremediavelmente entrelaçadas e que a política altera a economia e a economia afeta a política. A consolidação dessa visão possibilitou avanços na compreensão do comportamento de governos e a reação das sociedades. Esse entrelaçamento se constituiu ao longo do tempo como uma poderosa ferramenta para todos os interessados em mudar governos e transformar sociedades. ${ }^{4}$

Um dos maiores desafios que o Brasil terá de superar reside na atuação de um governo disfuncional, que tenta operar por meio de uma equipe econômica ultraliberal no comando de políticas que terão, obrigatoriamente, de se valer do suporte do estado, tido e havido como o vilão a ser reduzido à insignificância. ${ }^{5}$

A súbita inversão de papeis, de regras e leis que geraram uma imprevista desorganização estrutural no país coloca a necessidade de se refazer a engenharia institucional da sociedade brasileira, de seus negócios, da política e da vida, para que seu DNA seja mais humano, seguro e civilizado. 
As atividades de produção de conhecimento, de geração de métricas e dados confiáveis para o desenho de políticas públicas eficientes ocuparão um lugar especial nesse cenário. Ao não valorizar devidamente a $C \& T$, que sofre constantes cortes de verbas e não é efetivamente tomada como prioridade, $\mathrm{o}$ Brasil fragilizará ainda mais o sistema de inovação a duras penas construído nos últimos 30 anos. Um paradoxo flagrante, dada a intensa atividade de milhares de pesquisadores que transformaram as universidades em epicentros da busca acelerada de soluções para a Covid-19.

A ciência brasileira superou-se na identificação rápida das ameaças do coronavírus e desenvolveu mecanismos de proteção que ajudaram a mitigar seus efeitos devastadores. A duras penas, pois o desdém do governo pela ciência nunca demonstrou qualquer disposição para a trégua.

No Brasil, a pesquisa científica projetou-se como uma das primeiras no mundo a sequenciar o genoma do vírus e a replicá-lo em laboratório, o que permitiu a realização de testes em todo o país. Redes de pesquisa foram criadas. As Universidades, públicas e privadas, se mobilizaram em todos os campos e áreas, nas exatas, biológicas e nas humanidades. Para além da assistência, instituições hospitalares agiram em parceria com instituições públicas para a realização de testes e pesquisa. Institutos nacionais estaduais e municipais, a exemplo do Centro Nacional de Pesquisa em Energia e Materiais (CNPEM), se concentraram na busca de novos medicamentos. Agências de fomento (como CNPq, Finep, Embrapii, Fapesp) associaram-se a entidades ligadas à inovação (como Senai) e anunciaram programas de emergência voltados para se encontrar soluções em todos os âmbitos da crise: na saúde, na gestão, na produção de dados confiáveis, no controle de casos, na previsão, na fabricação de equipamentos e de medicamentos. Desse ponto de vista, a mobilização nacional continua ampla e solidária, similar à ocorrida em grande parte dos países assolados pela Covid-19. Apesar de todas as fragilidades, a resposta dos pesquisadores brasileiros mostrou-se mais do que relevante.

O flagrante descaso oficial celebrado por autoridades com ataques e desvalorização da ciência e das universidades antes da eclosão da crise atual mostrou-se desprezível diante da efervescente atuação da comunidade científica brasileira, que aprofundou as sinergias entre as engenharias, a física, a química, a biologia e em todas as áreas de humanidades, da economia à sociologia, da ciência política à psicologia.

A forte disposição demonstrada pela comunidade acadêmica foi fundamental para dar uma dose de credibilidade às medidas de distanciamento físico promovidas por vários governos estaduais e municipais, em aberto contraste com o comportamento errático da Presidência da República e, mais recentemente, do próprio Ministério da Saúde.

A velocidade da resposta permitiu entrever o enorme potencial que o Brasil possui para a geração de conhecimento voltado para o desenvolvimento do 
país. Disposição semelhante também percorreu o universo de startups, marcado pela busca e propagação de soluções para a crise. Ainda que em um grau menor, preocupações nesse sentido também estiveram presentes em médias e grandes empresas, em especial as mais inovadoras. Embora em número reduzido, várias se engajaram na fabricação e manutenção de equipamentos e instrumentos de segurança. Mais importante ainda, o Brasil pode assistir ao nascimento de um inédito movimento de grandes e médias empresas que se comprometeram a não demitir seus funcionários durante a crise.

Comportamento semelhante se observou em várias agências de fomento, que anunciaram programas e editais de apoio à busca de soluções para a Covid-19. Mesmo assim, é fundamental que as agências incorporem rapidamente o senso de urgência que a crise exige. Dados divulgados pelo Ipea indicam que as principais agências anunciaram editais que, em seu conjunto, mostram-se excessivamente tímidos quando comparados ao investimento de emergência decidido em países como China, Índia, Estados Unidos, Canadá, Reino Unido e Alemanha. A comparação não se prestou apenas para afirmar que o dispêndio brasileiro é menor do que outros países, mas para reforçar a necessidade urgente do país apoiar a ciência brasileira.

Pesquisa inédita veiculada pela Rede de Pesquisa Solidária mostrou que o investimento inexpressivo em pesquisa e inovação no Brasil durante a crise vai comprometer a recuperação da economia e a necessária reorganização da sociedade. ${ }^{6}$

Quadro 1 - Ações em pesquisa e inovação para fazer frente à crise da Covid-19

\begin{tabular}{|l|l|r|r|r|r|r|}
\hline \multicolumn{2}{|c|}{ Açöes adotadas/países } & EUA & Reino Unido & Canadá & Alemanha & \multicolumn{1}{|c|}{ Brasil } \\
\hline \multirow{2}{*}{$\begin{array}{l}\text { Novos } \\
\text { recursos } \\
\text { para P\&D e } \\
\text { Inovação }\end{array}$} & Em moeda local & $6,1 \mathrm{bi}$ & $1,3-1,35 \mathrm{bi}$ & $1,3 \mathrm{bi}$ & $2,1 \mathrm{bi}$ & $0,47 \mathrm{bi}$ \\
\cline { 2 - 7 } & $\begin{array}{l}\text { Em US\$ do oçamento } \\
\text { federal em P\&D* }\end{array}$ & $4,1 \%$ & $10,8 \%$ & $11,8 \%$ & $6,3 \%$ & $1,8 \%$ \\
\hline $\begin{array}{l}\text { Grupo cientifico de } \\
\text { assessoramento ao governo } \\
\text { federal }\end{array}$ & NÃO & SIM & SIM & SIM & NÃO \\
\hline $\begin{array}{l}\text { Mecanismo de aprovação } \\
\text { rápida de projetos de pesquisa e } \\
\text { inovação relacionados à Covid-19 }\end{array}$ & SIM & SIM & NÃO & NÃO & NÃO \\
\hline
\end{tabular}

A taxa de câmbio utilizada para a conversão para US\$ foi a vigente no dia $02 / 03 / 2020$ * $O$ cálculo desse percentual objetiva apenas estabelecer uma medida padronizada de esforço entre os países. Não significa que tenha havido um crescimento percentual, desta magnitude, nos investimentos em P\&D dos países, dado que algumas medidas adotadas não são P\&D, mas crédito ou investimento em empresas. O valor do orçamento federal desses países aplicado em P\&D foi obtido no site da OCDE: na Alemanha foi de $€$ 33,5 bi em 2019; no Canadá, CAD\$ 11 bi em 2017; no Reino Unido, €12 bi em 2017 e; nos EUA, US\$ 148 bi em 2019. Para o Brasil: www.mctic.gov.br/mctic/opencms/indicadores/detalhe/recursos_ aplicados/governo_federal/2.2.1.html, o valor foi de R\$25,7 bi de reais correntes em 2017. Elaboração das autoras.

Fonte: Rede de Pesquisa Solidária, Boletim \#6, 15.05.2020, p.9. 
As recomendações para as políticas públicas não poderiam ser mais claras:

- A saída efetiva da crise depende da capacidade humana de produzir vacinas, medicamentos e tratamento adequado para a Covid-19. Por isso, além das medidas de controle da pandemia e suas consequências econômicas e sociais, muitos países ampliam o investimento em pesquisa $\mathrm{e}$ em inovação e desenham novas estratégias científicas contra o vírus e de preparação para o pós-crise.

- Somente nos Estados Unidos foram alocados mais de US\$ 6 bilhões exclusivamente para pesquisas sobre a Covid-19, cerca de 4\% do investimento em P\&D realizados pelo governo em 2019. O Canadá ampliou em cerca de $12 \%$ os investimentos federais em P\&D. E novas políticas públicas na Alemanha e Reino Unido procuram garantir e acelerar sua capacidade de recuperação no pós-crise.

- A tradicional dependência científica e tecnológica do Brasil se tornou visível para a população com a escassez de equipamentos e testes para o combate à Covid. Essas lacunas poderiam ser minimizadas com uma estratégia coordenada de investimento em $\mathrm{P} \& \mathrm{D}$, o que até agora não ocorreu.

- O governo federal publicou apenas poucos editais com resultados previstos para junho-julho. O que significa que até o momento, o governo brasileiro não está financiando nenhuma pesquisa sobre a doença com recursos novos. O que é chocante, não tanto pelo volume menor investido pelo governo, mas pela inação diante da crise. Mesmo com recursos menores, o Brasil poderia fazer muito mais.

- Esse posicionamento do governo federal condena o Brasil a ser apenas um usuário de C\&T. A exemplo do que ocorreu em outras pandemias de menor porte, sem estratégias para o desenvolvimento e participação no esforço internacional pela pesquisa, o país corre o risco de ficar sem acesso às vacinas, equipamentos e insumos médicos, historicamente orientados para abastecer os países com maior competência científica e maior musculatura financeira.

A leitura dos editais brasileiros mostra que seus objetivos nem sempre estão sintonizados com as prioridades de pesquisa da Organização Mundial da Saúde e/ou dos centros reconhecidamente mais dinâmicos e que, em grande parte, foram desenvolvidos isoladamente, sem se orientar por uma coordenação nacional de esforços (De Negri et al., 2020).

O Brasil tem condições de reforçar seu lugar no mundo da C\&T. Mas é preciso foco, financiamento e definição de prioridades, pois sem o apoio público de longo prazo e educação de qualidade o país colherá apenas soluços científicos e tecnológicos.

Para isso, é essencial não deixar escapar as oportunidades de sinergia com o atual movimento que galvanizou a comunidade científica. Nesse sentido, a 
pró-atividade das agências de fomento é peça-chave para necessidades que emergem marcadas pela excepcionalidade.

E, como contribuição, seguem sete sugestões para o debate que podem fazer a diferença no apoio à pesquisa.

1. Modificar transitoriamente os processos de inscrição, avaliação e prestação de contas de projetos de pesquisa, seja de empresas, seja da academia.

2. Simplificar os procedimentos regimentais, de modo a acelerar o depósito, a aprovação e a prestação de contas das propostas.

3. Concentrar a avaliação dos projetos na (i) capacidade do pesquisador principal; (ii) na composição de sua equipe; (iii) na eficiência e idoneidade da instituição de origem; (iv) no histórico de cumprimento de compromissos de projetos anteriores.

4. Os países avançados possuem sistemas legais de excepcionalidade que dão conforto aos seus governos para licenciar ou se utilizar de patentes de interesse público. Esse também é um caminho que o Brasil deveria seguir e que permitiria agilizar a fabricação de equipamentos que, em tempos normais, teria referência no sistema patentário internacional.

5. Facilitar ainda mais o entrosamento e a cooperação internacional. Este é o momento de o país dar um salto na participação nas principais redes de pesquisa mundial. As agências de fomento, em conjunto com as universidades, podem estruturar sistemas de prospecção das redes mais dinâmicas e competentes do universo da ciência e abrir caminho para a associação de pesquisadores e instituições brasileiras, sejam as universitárias, sejam as empresariais.

6. Abrir diálogo imediato entre as principais universidades empresas de modo a viabilizar o desenvolvimento conjunto de soluções. Protótipos e projetos novos precisam sair dos laboratórios em linha com a produção industrial. Sem essa articulação corre-se o risco de uma ótima ideia se mostrar ineficiente quando confrontada com a realidade empresarial que exige rigor, escala e malha de fornecedores para ganhar realidade.

7. Consolidar a preocupação de grupos e de empresas que reconheceram a necessidade do apoio e financiamento privado à pesquisa. Mesmo que conjuntural, a decisão é oportuna e rara na história do país. Impulsionar a evolução dessa elite empresarial, seja via cooperação, seja a construção de fundos privados de investimento em C\&T, pode abrir perspectivas ainda não trilhadas sistematicamente no Brasil.

\section{A Covid-19 mudou o modo como se produz conhecimento}

$\mathrm{O}$ combate à pandemia exigiu a utilização de toda a capacidade científica disponível, no mundo e no Brasil. Foi a maneira de se alcançar resultados nos curto e médio prazos. No longo prazo, porém, é preciso que os esforços alcancem expressão institucional, única forma capaz de garantir longevidade e proteção contra os humores e oscilações da política e da falta de estratégia para C\&T. As crises passam, por mais dolorosas que sejam. Mas as instituições po- 
dem permanecer e indicar caminhos sólidos para uma inflexão na Universidade e na pesquisa brasileira. Para isso, além do esforço para a elaboração de políticas e programas de longa duração, é fundamental que as universidades se abram para o debate e para a reflexão sobre suas práticas e estruturas, a começar por seu relacionamento com a sociedade. A estanqueização promovida pelos departamentos mais atrapalha do que ajuda a pesquisa atual que é, essencialmente, multidisciplinar e multi-institucional. Todo avanço na sinergia entre disciplinas é chave para a reformatação da Universidade em sintonia com os novos tempos.

Certamente as sete recomendações apresentadas brevemente não são de fácil realização. Constituem-se, na verdade, em pontos para a reflexão que podem contribuir para colocar a C\&T no Brasil em sintonia com o que se faz de mais avançado no mundo. Isso porque:

1. A cooperação irrompeu com força, em especial pela estatura dos desafios de compreensão dos mecanismos sutis do coronavírus, que não consegue obter sucesso a não ser com a interação e fusão de estratégias diversificadas.

2. A pandemia quebrou algumas práticas não desejadas, mas que sempre estiveram presentes na atividade científica. A transparência e a precisão metodológica diante das pressões da Covid-19 tornaram difíceis a preservação de espaços "secretos" e "quase proprietários" da pesquisa voltados para inibir potenciais competidores.

3. Assim como o vírus, a pesquisa foi levada a superar as fronteiras nacionais, em contraste com o discurso nacionalista rasteiro de vários governos, a começar do brasileiro.

4. Uma das medidas de abertura à nova cooperação pode ser vista pela profusão de bancos de artigos veiculados publicamente antes da revisão por pares e a publicação em revistas científicas indexadas. Esses bancos foram inundados por artigos que apresentaram a pesquisa para a comunidade acadêmica e empresarial em todo o mundo, deixando em aberto a avaliação de seus eventuais sucessos e fracassos.

5. Apesar do tom antiglobalização adotado por alguns governos, como o dos Estados Unidos, da China e do Brasil, o que se viu foi uma explosão de artigos científicos e seus resultados expostos à avaliação pública.

\section{Encontro marcado com a educação de qualidade e a remodelagem da $C \& T$}

Os países que se destacam na busca de soluções para a Covid-19 investiram fortemente na capacitação e na formação das pessoas, desde os primeiros passos escolares. É o que está na base da valorização de sistemas como o STEM (acrônimo em inglês para Ciência, Tecnologia, Engenharia e Matemática), ou STEAM (que inclui o design, a criatividade e as humanidades), que orientam sistemas educacionais que têm o olho no futuro. $\mathrm{O}$ incentivo à participação de jovens na solução de problemas reais é a matéria-prima das engenharias, que oferece metodologias para o cultivo tanto das chamadas hard quanto das soft 
skills. Os números recentes do Anuário Brasileiro-Todos pela Educação, ${ }^{7}$ porém, deixam claro que o Brasil forma pouco e mal os alunos nos campos críticos para a nova geração de tecnologias.

O preço que pagamos pela falta de qualidade da nossa educação se manifesta nas dificuldades e na baixa produtividade da nossa economia. É certo que as empresas brasileiras ainda investem pouco em pesquisa e desenvolvimento. Mas não há como ignorar que muitas empresas diminuem sua ambição tecnológica por conta da falta de estímulo e apoio público, assim como dos obstáculos que encontram no ambiente para a inovação.

A qualidade e o volume do engajamento dos pesquisadores em todo o mundo abriram perspectivas novas para o reconhecimento dos méritos da atividade científica e de sua importância para a vida das pessoas. É possível que as C\&T terão condições de abrir um novo capítulo em sua história após a maré tóxica do coronavírus.

Nada será tranquilo, porém, dado que o mundo e o Brasil estarão mais pobres, com as finanças exauridas, provavelmente marcados por inflação, desemprego e com o agravamento das desigualdades sociais, principal obstáculo ao desenvolvimento.

As dores do parto de um novo ambiente para C\&T no Brasil, com financiamento adequado e estabilidade, capaz de formar novas e vibrantes gerações de cientistas dependem das respostas a serem formuladas e incorporadas na sociedade.

Trata-se, porém, de uma disputa em aberto, tanto de espaço quanto de prioridade, que depende muito, ainda que não exclusivamente, das universidades e das iniciativas da comunidade científica.

No Brasil, a crise é na saúde, na economia e na política. Contém ainda viés de alta para a eclosão de uma crise social, gerada pela regressão do PIB e pelo esgotamento da capacidade do Estado.

Como será a repercussão desse novo ambiente nas universidades, nos centros de pesquisa, na comunidade científica? Será que as práticas de cooperação intensa e internacionalização serão encarnadas em instituições ou se dissolverão com a crise?

É cedo ainda. O que se pode intuir é que os caminhos tradicionais de recuperação estarão vedados ou repletos de obstáculos. E se o futuro for tomado como ameaça, a ciência permanecerá eterna coadjuvante, precisamente quando a reorganização do país pede uma ciência protagonista.

Aos profissionais da ciência e da tecnologia cabe preservar a sintonia com as necessidades de milhões de brasileiros que buscam uma vida mais decente e mais segura. Uma vida que nunca tiveram antes do vírus, que piorou durante a crise e que tende a não melhorar após a onda destruidora atual.

No enfrentamento da crise a mídia, as revistas científicas, blogs e podcasts transmitiram o pronunciamento dos cientistas e profissionais da saúde e deram 
confiança à população e credibilidade a decisões excepcionais, como o distanciamento físico. O pós-crise espera que milhares de cientistas mostrem disposição para repensar a educação, o sistema de saúde, o modo de trabalhar e de viver em nosso país.

A ciência que investiga e joga luz no irreconhecível precisa ocupar um lugar de destaque na sociedade, por seus méritos, dedicação e capacidade de preparar caminhos mais saudáveis para a humanidade. Um esforço voltado para redesenhar a sociedade brasileira, que hoje sangra em seus fundamentos, inclusive nos democráticos.

Um novo sistema nacional de C\&T deve ser estruturado. A comunidade de pesquisadores de todos os cantos do país precisa se reunir, debater e propor um novo modo de se fazer ciência no país. Um Encontro Nacional de Cientistas, de todas as áreas e regiões, pode dar voz e unificar esse esforço.

A velocidade de expansão da Covid-19 derruba as economias e dilacera sociedades. Seu impacto desvela a extrema vulnerabilidade do mundo atual, que não tem apenas sua saúde abalada, mas sofre também com as mudanças do clima e pelo cortejo de enchentes, secas, migrações, falta de alimentos e de água que apenas ocasionalmente incomodam a consciência de planejadores e governantes. São ameaças ao que se costuma chamar de civilização, condição mutilada por um nível insustentável de desigualdade econômica e social, que rebaixa permanentemente o Brasil e a humanidade dos brasileiros.

\section{Notas}

1 Diretor do Instituto Nacional de Alergias e Doenças Infecciosas dos Estados Unidos, principal assessor da Casa Branca no combate a epidemias há 36 anos. New York Times, 09.06.2020. No original : "In a period of four months, it has devastated the whole world... Where is it going to end? We're still at the beginning of it" (tradução do autor).

2 Boletim \#2 da Rede de Pesquisa Solidária, abril de 2020. Nota Técnica coordenada por Rogério Barbosa e Ian Prates.

3 Boletim \#3 da Rede de Pesquisa Solidária, maio de 2020. Nota Técnica coordenada por Rogério Barbosa e Ian Prates.

4 No original: "Political economy is the integration of political and economic factors in our analysis of modern society. Inasmuch as just about everyone would agree that politics and economics are intricately and irretrievably interwoven - politics affects the economy and the economy affects politics - this approach seems natural. It has proved itself powerful in understanding governments and societies; it can also be a powerful tool for those interested in changing governments and societies" (tradução do autor).

5 A se basear na baixa eficiência dos programas emergenciais elaborados (como o apoio às empresas e aos trabalhadores que, em geral, deram subcobertura para quem precisa e sobre cobertura para quem não precisa) haverá um longo caminho a percorrer.

6 Rede de Pesquisa Solidária, Boletim \#6, 15 de maio de 2020, páginas 1-2. Nota Técnica coordenada por Fernanda De Negri.

7 Anuário Brasileiro da Educação Básica 2019. Todos pela Educação. Ed. Moderna. 
Referências

FRIEDEN, J. The Political Economy of Economic Policy. Finance \& Development, June 2020. p.9

DE NEGRI, F. et al. Ciência e Tecnologia frente à pandemia. Brasília: Centro de Pesquisa em Ciência, Tecnologia e Sociedade, Ipea, 2020.

RESUMO - A atual crise gerada pela Covid-19 já deixou em seu rastro pelo menos três grandes marcas: a primeira está cravada no alto custo em vidas e sequelas que feriram populações imensas em um curto tempo; a segunda responde pela aguda recessão e consequente diminuição do emprego, de salários e de renda, fechamento de empresas e desorganização da economia, com aumento das desigualdades e da pobreza; a terceira está ligada à corrosão institucional e à disseminação do medo e da perplexidade na sociedade. A ciência brasileira participa ativamente do esforço para mitigar os efeitos perversos da crise provocada pela pandemia que sacode o planeta, apesar da desvalorização promovida por autoridades brasileiras. As Universidades no mundo e no Brasil aceitaram rapidamente os desafios colocados pelo coronavírus, orientando-se pela busca obstinada de salvar vidas. Esse esforço tem condições de ser incorporado institucionalmente, para subsistir no tempo e contribuir para a elevação do patamar de impacto econômico e social da Ciência e da Tecnologia (C\&T) no Brasil.

PALAVRAS-CHAVE: Inteligência Artificial, Ética, Transparência, Black box, Explicabilidade.

ABSTRACT - The current crisis generated by Covid-19 has three major characteristics: first, the high cost in terms of lives and sequelae that have injured and killed a huge number of people in a very short period of time; second, the severe recession and the consequent reduction in employment, wages and income, not to mention the closing of companies and disorganizing of the economy, with an increase in inequality and poverty; third, the institutional corrosion and the dissemination of fear and perplexity in society. Brazilian science actively participates in the efforts to mitigate the perverse effects of the crisis caused by the pandemic, despite its depreciation by government authorities. Universities around the world and in Brazil quickly accepted the challenges posed by the coronavirus and guided their actions to save lives. This effort can be institutionalized to survive over time and contribute to increase the economic and social impact of Brazilian science and technology.

KEYWORDS: Artificial Intelligence, Ethics, Transparency, Black Box, Explicability.

Glauco Arbix é professor titular do Departamento de Sociologia da Faculdade de Filosofia, Letras e Ciências Humanas da Universidade de São Paulo, coordenador do Observatório da Inovação do Instituto de Estudos Avançados da USP, membro da Coordenação da Rede de Pesquisa Solidária. Ex-presidente do Instituto de Pesquisa Econômica Aplicada (Ipea) e da Financiadora de Estudos e Projetos (Finep). @ - garbix@usp.br / https://orcid.org/0000-0002-7078-4328.

Recebido em 10.6.2020 e aceito em 25.6.2020.

I Faculdade de Filosofia, Letras e Ciências Humanas, Universidade de São Paulo, São Paulo, Brasil. 